\title{
Delayed sternal closure after total artificial heart implantation
}

\author{
Sotirios Spiliopoulos, MD, ${ }^{\mathrm{a}}$ Ruediger Autschbach, MD, ${ }^{\mathrm{b}}$ Reiner Koerfer, MD, ${ }^{\mathrm{a}}$ and Gero Tenderich, MD, \\ Duisburg and Aachen, Germany
}

See related commentary on pages $418-20$.

One of the issues of greatest concern in total artificial heart (TAH) therapy is excessive bleeding in the early postoperative setting. Impaired perfusion, in cases of extended myocardial infarction and cardiogenic shock, and increased filling pressures, in cases of chronic biventricular heart failure, result in hepatic dysfunction and coagulation disorders. ${ }^{1}$ It is therefore not surprising that reexploration rates are still high. ${ }^{2}$ Although delayed sternal closure (DSC) is a well-established option for the management of refractory bleeding after routine and especially pediatric cardiac surgery, ${ }^{3-5}$ its safety and efficacy have still not been evaluated in the context of TAH therapy.

\section{MATERIALS AND METHODS}

Between July 2011 and August 2014, a total of 27 white, male patients received the SynCardia Total Artificial Heart (SynCardia Systems, Inc, Tucson, Ariz). Primary sternal closure (PSC) was performed in 16 cases. DSC was performed in 11 cases because of refractory bleeding, defined as persistent nonsurgical bleeding despite intense hemostatic therapy. The sternal wound was temporarily closed with a polytetrafluoroethylene membrane (W. L. Gore \& Associates, Inc, Medical Products Division, Flagstaff, Ariz) sewn to the skin edges with a monofilament suture. Dressings were changed daily in an aseptic manner. To prevent bacterial infections caused by Streptococcus and Staphylococcus species of grampositive bacteria as well as by Corynebacterium species and enteric gram-negative bacilli commonly colonizing the skin, patients were treated parenterally with $2 \mathrm{~g}$ cefazolin sodium [INN cefazolin] every 4 hours. Definite sternal closure was performed at a median of 3 days (range, 1-7 days). Criteria for timing of sternal closure were as follows: negative total fluid balance, stable TAH performance, and absence of any coagulation disorder or bleeding. Patient data were reviewed retrospectively.

\section{RESULTS}

Except for ischemic cardiomyopathy, which was the most frequent diagnosis in the DSC group (PSC 10/11

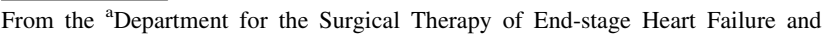
Mechanical Circulatory Support, Heart and Vascular Center Duisburg, Duisburg, Germany; and the ${ }^{\mathrm{b}}$ Department of Thoracic and Cardiovascular Surgery, RWTH University Aachen, Aachen, Germany.

Disclosures: Authors have nothing to disclose with regard to commercial support. Received for publication Feb 18, 2015; revisions received April 9, 2015; accepted for publication April 25, 2015; available ahead of print June 3, 2015

Address for reprints: Sotirios Spiliopoulos, MD, Heart and Vascular Center Duisburg, Department for the Surgical Therapy of End-stage Heart Failure and Mechanical Circulatory Support, Fahrner St 133-135, 47169 Duisburg, Germany (E-mail: sotirios.spiliopolos@ejk.de).

J Thorac Cardiovasc Surg 2015;150:417-8

$0022-5223 / \$ 36.00$

Copyright (C) 2015 by The American Association for Thoracic Surgery

http://dx.doi.org/10.1016/j.jtcvs.2015.04.057
}

TABLE 1. Examined postoperative variables

\begin{tabular}{lccc}
\hline \multicolumn{1}{c}{ Variables } & $\begin{array}{r}\text { Primary sternal } \\
\text { closure }(\mathbf{n}=\mathbf{1 6})\end{array}$ & $\begin{array}{c}\text { Delayed sternal } \\
\text { closure }(\mathbf{n}=\mathbf{1 1})\end{array}$ & $\begin{array}{c}\boldsymbol{P} \\
\text { value }\end{array}$ \\
\hline $\begin{array}{l}\text { Transfusion requirements } \\
\text { (RBC, FFP, and total }\end{array}$ & $10,5(4-24)$ & $14(8-24)$ & .04 \\
platelet units, median & & & \\
$\quad$ and range) & & & \\
Reoperation for tamponade & $10 / 16$ & $3 / 11$ & .03 \\
Sternal infection & $0 / 16$ & $1 / 11$ & .11 \\
Acute renal failure & $12 / 16$ & $4 / 11$ & .02 \\
Long-term ventilation & $8 / 16$ & $2 / 11$ & .04 \\
Hospital stay (d, median & $93(38-209)$ & $54(33-160)$ & .05 \\
$\quad$ and range) & & & \\
Mortality at 90 d & $3 / 16$ & $5 / 11$ & .13 \\
\hline
\end{tabular}

Data represent numbers of patients except as noted. Statistical comparisons were made by 2 -tailed $t$ test. RBC, Red blood cell; FFP, fresh-frozen plasma.

vs DSC: $7 / 16 ; P=.005$ ), preoperative characteristics, including Interagency Registry for Mechanically Assisted Circulatory Support (INTERMACS) profiles (INTERMACS 1 , PSC $7 / 16$ vs DSC $6 / 11 ; P=.29$; INTERMACS 2 , PSC $9 / 16$ vs DSC $5 / 11 ; P=.29)$, preoperative extracorporeal membrane oxygenation support (PSC 5/16 vs DSC $5 / 11 ; P=.23$ ), patient age (PSC median 63 years and range 41-74 years vs DSC median 64 years and range 51-70 years; $P=.14$ ), and intention to treat as bridge to transplant (PSC $12 / 16$ vs DSC $8 / 11 ; P=.44$ ), were similar between the groups. Postoperative results are listed in Table 1. Periprocedural transfusion requirements were significantly higher in the DSC group $(P=.04)$. Reoperation for tamponade was more frequent in the PSC group $(P=.03)$. Similarly, both long-term ventilation, defined as ventilatory support longer than 6 days necessitating tracheostomy, and acute renal failure, defined as temporary need for hemodiafiltration or prolonged need for recombinant B-type natriuretic peptide infusions ( $>5$ days) were more frequent in the PSC group ( $P=.04$ and $P=.02$, respectively). Duration of hospital stay was shorter in the DSC group $(P=.05)$. There were no significant differences in overall mortality at 90 days $(P=.13)$. One of the patients in the DSC group had a deep sternal wound infection develop; this was successfully treated with vacuum-assisted closure therapy.

\section{DISCUSSION}

As has been previously reported, the incidence of bleeding complications in patients requiring reexploration after TAH implantation is relatively high and correlates with 30- day survival. ${ }^{6}$ In this study, we examined the impact of DSC on the clinical outcomes of these patients. 
We demonstrated that, similar to the experience with DSC in left ventricular assist device recipients, ${ }^{7,8}$ this strategy for the management of refractory bleeding is effective because it breaks the cycle of pericardial tamponade and low-output events of the artificial ventricles and contributes to a decrease in major perioperative complications. As in the case of patients with LVADs, concerns regarding infection proved to be unfounded. There was a single case of deep sternal wound infection; however vacuum-assisted closure therapy was effective, and an infection of the TAH system was not documented. The main limitations of this study are retrospective data collection and analysis, as well as limited comparability of baseline data. For this reason, further possible implications of a general adoption of DSC strategy in routine operative management, such as a significant decrease in transfusion requirements and thus allogeneic sensitization, still have to be prospectively examined.

\section{References}

1. Alvarez AM, Mukherjee D. Liver abnormalities in cardiac diseases and heart failure. Int J Angiol. 2011;20:135-42.

2. Kirsch ME, Nguyen A, Mastroianni C, Pozzi M, Léger P, Nicolescu M, et al. SynCardia temporary total artificial heart as bridge to transplantation: current results at La Pitié hospital. Ann Thorac Surg. 2013;95:1640-6.

3. Furnary AP, Magovern JA, Simpson KA, Magovern GJ. Prolonged open sternotomy and delayed sternal closure after cardiac operations. Ann Thorac Surg. 1992;54:233-9.

4. Christenson JT, Maurice J, Simonet F, Velebit V, Schmuziger M. Open chest and delayed sternal closure after cardiac surgery. Eur J Cardiothorac Surg. 1996;10:305-11.

5. Samir K, Riberi A, Ghez O, Ali M, Metras D, Kreitmann B. Delayed sternal closure: a life-saving measure in neonatal open- heart surgery; could it be predictable? Eur J Cardiothorac Surg. 2002;21:787-93.

6. Copeland JG, Copeland H, Gustafson M, Mineburg N, Covington D, Smith RG, et al. Experience with more than 100 total artificial heart implants. J Thorac Cardiovasc Surg. 2012;143:727-34.

7. Schaffer JM, Arnaoutakis GJ, Allen JG, Weiss ES, Patel ND, Russell SD, et al. Bleeding complications and blood product utilization with left ventricular assist device implantation. Ann Thorac Surg. 2011;91:740-7; discussion 747-9.

8. Stulak JM, Romans T, Cowger J, Romano MA, Haft JW, Aaronson KD, et al. Delayed sternal closure does not increase late infection risk in patients undergoing left ventricular assist device implantation. J Heart Lung Transplant. 2012;31:1115-9.

\title{
EDITORIAL COMMIENTARY
}

\section{Delayed sternal closure after assist device implantation: Not all bleeding stops}

\author{
David D. Yuh, MD, FACC, FACS
}

See related article on pages $417-8$.

Since its initial description in the mid-1970s for "tight mediastinal syndrome," ${ }^{11}$ delayed sternal closure (DSC) has been adopted in pediatric and adult cardiac surgery as a temporizing strategy in the setting of severely impaired cardiac function or uncontrollable hemorrhage. ${ }^{2-6}$ Fortunately, most of the published experience with this strategy, including patients undergoing ventricular assist device implantation, ${ }^{7}$ describes successful outcomes with

From the Section of Cardiac Surgery, Yale University School of Medicine, New Haven, Conn.

Disclosures: Author has nothing to disclose with regard to commercial support.

Received for publication May 11, 2015; accepted for publication May 12, 2015; available ahead of print June 11, 2015.

Address for reprints: David D. Yuh, MD, FACC, FACS, Section of Cardiac Surgery, Yale University School of Medicine, 333 Cedar St, PO Box 208039, New Haven, CT 06520 (E-mail: david.yuh@yale.edu).

J Thorac Cardiovasc Surg 2015;150:418-20

$0022-5223 / \$ 36.00$

Copyright (c) 2015 by The American Association for Thoracic Surgery

http://dx.doi.org/10.1016/j.jtcvs.2015.05.037 the use of DSC. Surprisingly, low rates of mediastinitis or device colonization, presumably due to meticulous attention to sterility, antibiotic prophylaxis, and expedient wound closure, have been the norm rather than the exception in these published series.

Spiliopoulos and colleagues ${ }^{8}$ have taken this precedent further by reporting the successful use of DSC for the management of intractable bleeding in patients implanted with the SynCardia total artificial heart (TAH) (SynCardia Systems Inc, Tucson, Ariz) system. The investigators observed a lower incidence of prolonged mechanical ventilation and acute renal failure with DSC compared with primary sternal closure (PSC), as well as shorter hospitalizations with no significant differences in overall mortality at 90 days. Moreover, only 1 of 11 patients in the DSC group developed a deep sternal wound infection with no documented infection of the implanted device. By acknowledging the limitations of such a retrospective study and 